\title{
Scarlet fever can mimic toxic shock syndrome
}

\author{
M.G. Brook and B.A. Bannister \\ Royal Free Hospital Department of Infectious Diseases, Coppetts Wood Hospital, Coppetts Road, London \\ NIO IJN, UK.
}

\begin{abstract}
Summary: We describe a patient who presented with a widespread erythematous rash, diarrhoea, confusion, pre-renal uraemia and hyponatraemia. The diagnosis of staphylococcal toxic shock syndrome seemed likely as she was menstruating and there was no evidence of pharyngitis. A rising ASO titre confirmed a streptococcal aetiology and thus 'toxic' scarlet fever. Toxic shock syndrome and toxic scarlet fever are compared.
\end{abstract}

\section{Introduction}

Scarlet fever was a major cause of morbidity and mortality in the pre-antibiotic era. Although the term toxic shock syndrome has become synonymous with a staphylococcal related illness of rash and hypotension, such features would far more likely have had a streptococcal aetiology in the earlier part of this century. ${ }^{1-3}$ Scarlet fever still occurs, but the disease seen nowadays is usually no more severe than an uncomplicated streptococcal sore throat with the addition of a rash. ${ }^{4}$ It is unclear why the severe toxic form of the disease has become uncommon, but its incidence fell simultaneously with that of the other streptococcal complications: rheumatic fever and glomerulonephritis. ${ }^{1}$ Patients, particularly adult females, presenting with a severe illness associated with an erythematous rash would nowadays be most likely diagnosed as toxic shock syndrome (TSS). ${ }^{5-10}$ We present such a case which highlights the diagnostic pitfalls and shows that 'toxic' scarlet fever (TSF) has not completely disappeared. The clinical similarities between TSS and TSF are also reviewed and features of differentiation are stressed.

\section{Case report}

Seven days prior to admission a 40 year old married school teacher suddenly became ill with abdominal pain and diarrhoea. On the third day of illness a widespread erythematous rash, a temperature of $41^{\circ} \mathrm{C}$ and myalgia developed. Penicillin was commenced but changed to erythromycin one day

Correspondence: $\quad$ M.G. Brook, B.Sc., M.R.C.P., D.R.C.O.G., D.T.M.\&H., D.C.H.

Accepted: 5 July 1988 later because of tongue swelling. Two days before admission she became confused, anuric, had hiccoughs and abdominal distension. Tampons had been used from 3 days prior to the onset of the illness until admission.

On examination she was apyrexial, confused, disorientated and incoherent. There was a diffuse erythematous rash affecting the whole of the body, with peeling on the face, and petechiae and ecchymoses over the anterior lower limbs. There was neck stiffness but neurological examination was otherwise normal. There were no obvious sites of skin infection. The oropharynx was diffusely inflamed but the tonsils were not swollen and there was no exudate. There was minimal uterine bleeding, a mildly inflamed cervix and a small amount of maladorous discharge. There was no pelvic tenderness or induration. The blood pressure was $115 /$ $75 \mathrm{~mm} \mathrm{Hg}$ with a pulse of 100 beats/min.

Initial investigations revealed uraemia (urea $23.8 \mathrm{mmol} / 1$, creatinine $436 \mu \mathrm{mol} / 1$, potassium $4.6 \mathrm{mmol} / \mathrm{l}$ and urinary sodium $5 \mathrm{mmol} / \mathrm{l})$, hyponatraemia $(113 \mathrm{mmol} / \mathrm{l})$, hypocalcaemia $(1.92 \mathrm{mmol} / \mathrm{l})$ and hypoalbuminaemia $(26 \mathrm{~g} / \mathrm{l})$ and biochemical evidence of myositis. The electrocardiogram was normal. There was mild anaemia $(10.7 \mathrm{~g} / \mathrm{l})$ with a leucocytosis (neutrophils $27 \times 10^{9} / 1$ ) and thrombocytopaenia $\left(90 \times 10^{9} / 1\right)$, but disseminated intravascular coagulation was excluded by normal clotting studies and absent fibrin degradation products. Liver function tests, cerebrospinal fluid, urine microscopy and urinalysis were normal.

Initial antibiotic treatment was with vancomycin and cefotaxime, and her initial recovery was rapid but later complicated by a gastrointestinal haemorrhage, fluid retention related to hypoalbuminaemia

(C) The Fellowship of Postgraduate Medicine, 1988 
and ileus. She was discharged fit and well 4 weeks after admission, with all laboratory tests normal.

Pathogenic organisms were not cultured from multiple swabs, presumably due to prior antibiotic treatment, and no site of infection was found, but a rising ASO titre from $200-400 \mathrm{IU} / \mathrm{ml}$ on admission to $3200 \mathrm{IU} / \mathrm{ml}$ at 4 weeks confirmed the diagnosis of toxic scarlet fever. The anti-staphylococcal antibodies, anti-staphylolysin and anti-nuclease, remained stable in low titres.

\section{Discussion}

Before the ASOT titre rise, the aetiological diagnosis was unclear. This emphasizes the considerable overlap between TSS and TSF. There were several features not typical of scarlet fever, including a lack of evidence of focal streptococcal infection in spite of attempts to isolate Streptococcus pyogenes from throat, vagina and ascites. Similarly, the uraemia, hyponatraemia and diarrhoea seen in this patient have been rarely reported in $\mathrm{TSF}^{11}$ although glomerulonephritis is a recognized late complication. ${ }^{5}$ It is possible that a low grade septicaemia had occurred in this patient and had responded to the antibiotics given at home. This might then explain the diarrhoea and pre-renal uraemia. ${ }^{12-14}$

The reported clinical features common to TSS and TSF include a widespread erythematous rash which later peels, headache, malaise, mucosal inflammation, confusion and myalgia. ${ }^{1-10}$ This is perhaps not surprising as the pyogenic toxin type A produced by scarlet fever-related strains of streptococci, and toxic shock syndrome toxin type I (TSST-1) produced by staphylococci isolated in cases of TSS have a similar structure. ${ }^{11,15,16}$ The mortality of TSF is unknown but is likely to be similar to the presently reported $5 \%$ for TSS. ${ }^{5}$

Both diseases can occur following skin infections $^{1-4,17}$ although TSF most commonly occurs as a complication of pharyngitis/tonsillitis ${ }^{1-4}$ and TSS in association with vaginitis during menstruation following tampon use. ${ }^{5-10}$ The other clinical features that would suggest TSF in cases of uncertainty include puncta and skin crease accentuation of the erythema (Pastia's sign). Illness in a male would also suggest TSF in a disease that has an equal sex incidence, whereas TSS has a 9:1 female

\section{References}

1. Dick, G.F. \& Dick, G.H. Symptoms. In: Scarlet Fever. The Year Book Publishers, Chicago, 1938, pp 35-52.

2. Musser, J.H. Scarlet fever. In: Pullen, R.L. (ed) Communicable Diseases. Henry Kimpton, London, 1950, pp 69-79. predominance. The incidence of hypotension, renal failure and hepatic dysfunction in TSF is unclear as there are few descriptions in recent literature ${ }^{11}$ and accounts from earlier in the century use nonspecific terms such as 'toxaemia' and 'collapse'. These complications are common in $\mathrm{TSS}^{5-10}$ and their presence would also suggest the latter diagnosis.

Laboratory data on TSF are sparse as most published accounts were written from the preantibiotic era. ${ }^{1-3} \mathrm{~A}$ recent report of two cases of atypical TSF suggests that hepatic and renal dysfunction does occur ${ }^{11}$ whereas these complications are well recognized in TSS. ${ }^{5-10}$ Although altered muscle enzymes have not previously been reported in TSF, the frequent description of clinical myositis suggests that this test would be abnormal with similar frequency in both conditions. Myocarditis is seen in up to $20 \%$ of cases of scarlet fever and would also cause increased muscle enzymes. ${ }^{5}$ Disseminated intravascular coagulation has also been reported in both TSS and TSF. ${ }^{5,7,11^{-}}$Features that would suggest TSS and not TSF include hypotension and diarrhoea. ${ }^{5-10}$ Diarrhoea has only been described as a rare pre-terminal complication of TSF $^{1}$ but has also been reported in severe streptococcal infections including septicaemia. ${ }^{12-14}$ Tampon use and vagino-cervicitis are features of over $90 \%$ of cases of TSS, ${ }^{5-10}$ although menstruation may be a non-causal coincidental association of TSF, as seen in the patient described.

In cases of infection originating outside the throat and vagina the initial diagnosis can be difficult, particularly in the common situation where the pre-admission use of antibiotics has prevented the early identification of organisms. The implication of this overlap is that antistaphylococcal antibiotics such as flucloxacillin or fusidic acid may be used after an incorrect diagnosis of TSS, and would provide suboptimal cover against streptococci. Benzylpenicillin is the drug of choice for streptococcal infection, and therefore TSF, but may be ineffective for up to $80 \%$ of staphylococcal isolates. ${ }^{18}$ At a time when TSS is in the forefront of medical literature ${ }^{8}$ and TSF thought to have virtually disappeared, ${ }^{5}$ TSF should be remembered in cases of 'atypical' TSS and antibiotic prescribing should be accordingly adapted.

3. Dowling, H.F. Streptococci infections. In: The Acute Bacterial Diseases. W.B. Saunders, London, 1948, pp 34-172.

4. Breese, B.B. Streptococcal pharyngitis and scarlet fever. Am J Dis Child 1978, 132: 612-616. 
5. Christie, A.B. Toxic shock syndromes. In: Infectious Diseases. Churchill Livingstone, London, 1987, pp. 12-16.

6. Todd, J., Fishaut, M., Kapral, F. \& Welch, T. Toxicshock syndrome associated with phage-group-1 Staphylococci. Lancet 1978, ii: 1116-1118.

7. Shandos, K., Schmid, G.B., Bruce, D.B. et al. Toxic shock sundrome in menstruating women. $N$ Engl $J$ Med 1980, 303: 1436-1442.

8. Eykyn, S.J. Toxic shock syndrome. Some answers but questions remain. $\mathrm{Br} \mathrm{Med} J$ 1982, 284: 1585-1586.

9. Neild, G. \& Cameron, J.S. Tampon shock. Lancet 1980, ii: 1196.

10. Anon. Toxic shock and tampons. Br Med J 1980, 281: 1426.

11. Cone, L.A., Woodare, D.R., Schlievert, P.M. \& Timory, G.S. Clinical and bacteriologic observations of a toxic shock-like syndrome due to Streptococcus pyogenes. N Engl J Med 1987, 317: 146-149.

12. Teall, A., Visuvanthan, S., Payne, A. \& Silverstone, A. Unsuspected streptococcal infection presenting with diarrhoea in late pregnancy. $J$ Infection 1987, 14: 185-186.
13. Thomas, P.S., Wilkins, E. \& Hickey, M. Streptococcus pyogenes and dysentery. J Infection 1988, 16: 200-201.

14. Ispahani, P., Donald, F.E. \& Avelio, A.J.D. Streptococcus pyogenes bacteraemia: an old enemy subdued but not defeated. $J$ Infection 1988, 16: 37-46.

15. Willoughby, R. \& Greenberg, R.N. The toxic shock syndrome and streptococcal pyrogenic exotoxins. Ann Intern Med 1983; 98: 559.

16. Johnson, L.P., L'Italien, J.J. \& Schlievert, P.M. Streptococcal pyrogenic exotoxin type A (Scarlet fever toxin) is related to Staphylococcus aureus enterotoxin B. $M G G$ 1986, 203: 354-356.

17. Rengold, A.L., Dan, B.B., Shandds, K.K.N. \& Broome, C.V. Toxic shock syndrome not associated with menstruation. Lancet 1982, i: 1-4.

18. Phillips, I. \& Eykyn, S.J. Staphylococci. In: Weatherall, D.J., Ledingham, J.G.G. \& Warrell, D.A. (eds) The Oxford Textbook of Medicine, vol. 2. Oxford Medical Publications, Oxford, 1987, 5: 191-198. 